\title{
Anim
}

\section{La asignatura de Historia del Trabajo Social en la Diplomatura de Trabajo Social}

\section{RAFAEL DíAZ FERnÁNDEZ}

DEPARTAMENTO DE PSICOLOGÍA Y SOCIOLOGÍA

UNIVERSIDAD DE ZARAGOZA

Resumen: La asignatura de Historia de Trabajo Social es enfocada para su estudio como un proceso progresivo de etapas que van dando paso de manera cronológica a la etapa posterior. Desde el punto de vista metodológico se fundamenta en el aprendizaje teórico-práctico. Una constante a lo largo de la historia ha sido la manera diferente en que se ha dado respuesta a las carencias de las personas, que debe ser conocida y analizada formando parte del contexto de cada época. Partiendo de la forma de respuesta a las necesidades sociales, como obligación de las familias, en las sociedades primitivas, pasando por los inicios de la ayuda organizada, para avanzar hacia la acción benéfico asistencial, hasta el surgimiento de la política social como responsabilidad del Estado y el nacimiento del Trabajo Social como profesión, se va analizando la situación socio económica y política de cada periodo de la historia, haciendo referencia a las diferentes figuras que han impulsado esta nueva profesión 
y han facilitado el nacimiento del Trabajo Social como disciplina y como profesión.

Palabras clave: Historia del Trabajo Social, acción benéfico asistencial, ayuda organizada, profesión, disciplina.

\section{The History of Social Work Course Module in the Diploma in Social Work}

Abstract: The course module of History of Social Work is focussed, for study purposes, as a progressive process in stages, which occur chronologically, each giving rise to a subsequent stage. From the point of view of the methodology, it is based on both theoretical and practical learning. Throughout history, there have always been different ways in which people's needs have been attended to, which must be known and analysed by placing them into the context of each era. Taking the different responses to social needs as a starting point -moving from the concept of family obligation in primitive societies to the emergence of organised care, the development of charitable welfare work, the creation of social policy as a State responsibility and the birth of Social Work as a profession - the social, economic and political situation of each historical period is analysed, making reference to the various individuals that have promoted this new profession and have contributed towards the creation of Social Work as a discipline and profession.

Keywords: History of Social Work, charitable welfare work, organised care, profession, discipline. 


\section{La asignatura de Historia del Trabajo Social en la Diplomatura de Trabajo Social}

\section{Introducción}

En este artículo se exponen los contenidos teóricos y prácticos de la asignatura de Historia del Trabajo Social que deben estudiar los futuros Diplomados en Trabajo Social para adentrarse en el conocimiento de los orígenes y evolución de esta profesión. Se pretende explicar a partir de la reflexión aquello que los alumnos deben saber respecto a las formas de ayudarespuesta ante las necesidades sociales a lo largo de la Historia, la incidencia de los denominados precursores del Trabajo Social, cuándo se organiza la asistencia social, por qué y cuando nace el Trabajo Social como profesión y disciplina, y las peculiaridades del proceso de nacimiento y evolución de la misma.

A través de los contenidos teóricos y prácticos se pretende alcanzar tres objetivos principales: 1) Conocer la génesis, historia y evolución del Trabajo Social 2) Analizar los hechos históricos y sociales que han configurado la profesión y 3) Conocer la historia y la situación actual del Trabajo Social en España y Aragón.

La asignatura se establece en torno a cuatro grandes bloques teóricos: las formas de dar respuesta a las necesidades sociales a lo largo de la historia, la asistencia social organizada, el nacimiento de la profesión, de la disciplina y el Trabajo Social en nuestros contextos geográficos más próximos. 


\section{Cómo vamos a enfocar la asignatura}

La historia del Trabajo Social se estudiará como un proceso progresivo de etapas válidas por sí mismas, pero como indican Las Heras y Cortajarena (1986:53) "al mismo tiempo se convierten en germen y preparación de otra etapa posterior más plena y más avanzada".

Partiremos de la relación que a lo largo de la historia se puede establecer entre los distintos modelos económicos en cada época (edad antigua, media, moderna y contemporánea), las revoluciones (francesa o burguesa, industrial y científica), los cambios políticos, la acción social, las políticas sociales, los servicios sociales, el Estado de bienestar, haciendo referencia a las situaciones que como consecuencia de todo ello afectaron a la población generando problemas sociales.

La asignatura es troncal y tiene una carga docente de tres créditos, treinta horas lectivas (veinticinco de ellas son teóricas y cinco prácticas), en la Universidad de Zaragoza, equivalentes a 2,6 créditos en el nuevo Sistema de Transferencia basado en el Crédito Europeo (ECTS) ${ }^{1}$. El eje de transmisión de conocimiento estará centrado en el aprendizaje del alumno no solo a través de la enseñanza teórica sino también del desarrollo de otros aspectos como son el conjunto de competencias profesionales según la Declaración de Bolonia.

Nos aproximaremos a la cuestión de la historia de esta profesión facilitando la comprensión de su significado desde la distinción entre la acción social, el trabajo social como un conocimiento práctico, el Trabajo Social como un conocimiento teórico con una orientación práctica y el Trabajo Social como un conocimiento teórico para así abordar el tema desde estas diferencias que caracterizan los distintos elementos que constituyen el trabajo social ${ }^{2}$.

La metodología aplicada está fundamentada en el aprendizaje teórico-práctico de la asignatura, combinando una biblio-

${ }^{1}$ ECTS, European Credit Transfer System.

2 Para Haluk Soydan (2003: 46) al diferenciar las formas de conocimiento de esta forma, también se corresponde con los conceptos duales del trabajo social como actividad práctica y como disciplina académica, siendo esta última equivalente a varios tipos de "conocimiento teórico". 
grafía específica sobre los contenidos teóricos y un material audiovisual (películas, documentales), lecturas de capítulos de libros, artículos sobre acontecimientos aparecidos en prensa u otros medios de comunicación de especial relevancia e interés. En primer lugar el alumno trabajará el material de forma individual, para posteriormente, en la clase práctica trabajar el documento de forma grupal (pequeños grupos), de modo que cada miembro del grupo realice su aportación elaborando las conclusiones finales a las que se llegará por consenso y que serán expuestas en el grupo grande.

En cuanto al desarrollo de las unidades didácticas, durante las sesiones, se pretende acercar a los alumnos a la realidad histórica a través de la realidad actual que es la que ellos conocen más y sobre la que tienen más información de modo que así pueda parecer más cercana e interesante, combinando los diferentes momentos de la historia. Para comprender la historia y evolución del trabajo social es preciso acercarnos a los diferentes contextos socioculturales de los elementos que participan ${ }^{3}$.

Se trata de hacer protagonista al alumno de su propia formación con autonomía y favoreciendo su participación para conseguir que la historia sea una asignatura motivante, iniciándolo en el conocimiento de que aunque la sociedad siempre intentó responder a las necesidades de los individuos, de acuerdo con el pensamiento político, socioeconómico y cultural, la profesión y la disciplina se configuraron a partir de la revolución industrial siglo XIX y principios del XX.

\section{Partimos de la realidad inicial impulsora del Trabajo Social: la} respuesta a las necesidades sociales a lo largo de la historia

Según percepción de los estudiantes, el conocimiento que del Trabajo Social tiene la sociedad de nuestros días encuentra su referente más cercano en los profesionales de su entorno

${ }^{3}$ Como señala Malcolm Payne (1995:25) "el trabajo social es una actividad socialmente construida”. Por lo tanto admitiendo su variación según las culturas podremos también entender su variación a lo largo de los diferentes momentos de la historia. 
que desempeñan esta profesión, como asistentes sociales en un pasado no muy lejano, trabajadores sociales actualmente, a través de la respuesta dada a las necesidades individuales o sociales del momento. Pero ayudar al necesitado, responder a las situaciones de necesidad no solo ha sido una constante histórica sino que se ha realizado de forma muy diferente a lo largo de la historia social de la humanidad. Desde la más remota antigüedad las sociedades han respondido ante las carencias de las personas o de los grupos y esta forma de respuesta ha sido diferente ${ }^{4}$ dependiendo de la época pero tendiendo hacia la búsqueda de recursos sociales, humanos o materiales, técnicos o institucionales. Ayudar a quienes lo necesitaban en las sociedades primitivas era obligación de la familia, del clan o de la tribu, algo que más tarde se convirtió en una cuestión humanitaria y religiosa, trascendiendo del ámbito del apoyo mutuo al del socorro de aquellos que no pertenecían a un círculo tan cercano. El interés por el conocimiento de como a lo largo de la historia ha evolucionado el modo en que se ha dado respuesta a las necesidades sociales ${ }^{5}$, es importante desde la perspectiva panorámica que ofrece de los antecedentes de lo que hoy podemos decir es el objeto ${ }^{6}$ de intervención de los trabajadores sociales

${ }^{4}$ Gaspar Sánchez y Teodoro Andrés (2005:24) señalan la importancia del conocimiento de los antecedentes lejanos respecto a las distintas formas de ayuda al necesitado a lo largo de la historia en "Introducción al Trabajo Socia" ayuda án Bricho. "Dependiendo de cada con "xo social de Aleman Bracho. "Dependiendo de cada contexto social, el hombre ha sentido la obligación de atender a las carencias de sus congéneres de una u otra forma, predominando el concepto de ayuda hacia las personas sin recursos suficientes para poder subsistir. Al estudiar cualquier sociedad por muy primitiva que sea, se repite esta constante. La forma de intervenir en las necesidades sociales, que genéricamente vamos a denominar asistencia social, ha revestido múltiples formas a lo largo de la historia a través de códigos de conducta, prescripciones, caridad, beneficencia filantropía ... hasta llegar a la ayuda profesionalizada dentro de

5 Tal como indica Zamanillo (1991:66-67-68) las necesidades sociales constituyen una parte del objeto de estudio del trabajo social, formando parte también del mismo:"el individuo o determinada clase de individuos; ciertas situaciones que sufren los individuos; las necesidades sociales como tipo específico de situación y los problemas sociales".

6 "El objeto de intervención del Trabajo Social es el espacio que se genera en el tránsito entre las necesidades y la satisfacción; es decir, entre la demanda de la población (individual, grupalo colectiva) y la (De la Red, 1993: $166)$ 
Para estudiar la historia del Trabajo Social consideramos necesario remontarse al estudio de esa forma diferente de respuesta que a lo largo de la historia se ha dado a las necesidades sociales en las diferentes civilizaciones para comprender mejor el objeto del trabajo social, y teniendo en cuenta que la historia del trabajo social realmente comienza a finales del siglo XIX, cuando comienza la profesión o cuando se inicia la disciplina $^{7}$ y a esa forma diferente de ayudar a los necesitados es lo que confiere al Trabajo Social la categoría de profesión.

\section{Los inicios de la ayuda organizada}

Para conocer los inicios de la ayuda organizada estudiaremos los siglos XV y XVI, en el contexto del Renacimiento, el período de la historia situado entre la Edad Media y la Edad Moderna, caracterizado por la supremacía de lo urbano sobre lo rural, el progresivo aumento de la pobreza en las ciudades y el movimiento Humanista con el hombre como centro del universo así como la importancia de este momento que constituye el inicio de nuevas propuestas de formas de intervención social pública y formas de tratamiento técnico para las situaciones de necesidad, comenzando así un nuevo cuestionamiento de qué hacer y cómo hacer y por lo tanto aunque no pueda afirmarse

${ }^{7}$ Como señala Miranda (2004: 40-41) "La historia del Trabajo Socia comienza cuando comienza el Trabajo Social, bien como profesión, es decir, cuando por primera vez aparecen mujeres (en su inmensa mayoría) que se ganan la vida desarrollando una serie de funciones muy concretas, acotando su terreno profesional, marcando distancias respecto al voluntariado, creando sus asociaciones profesionales, etc; o bien cuando se inicia la disciplina o lo que es asociacios lo mismo, cuando se empiezan a estructurar conocimientos especificos que $\mathrm{s}$ transmiten mediante las correspondientes actividades formativas en el seno de las organizaciones y agencias, primero, y en la Universidad, después. Por tanto nos estamos refiriendo a una época no anterior a la última década del siglo XIX. Todos los antecedentes formarán parte de los prolegómenos, serán los precursores o simplemente configurarán elementos de la historia de la solidaridad humana, de la acción social o de la política social. En consecuencia, afrontar con rigor de la historia del Trabajo Social, si por tal entendemos una disciplina que quiere ser científica y de una profesión en el sentido moderno del término, excluye remontarse al Código de Hammurabi, o hablar de Luis Vives o San Vicente de Paúl". 
que se lleve a cabo un planteamiento puramente metodológico, si significa el camino en esta nueva dirección, siempre desde una corriente humanista, cristiana como señala De la Red (1993:25). Este período lo vamos a estudiar a través de figuras relevantes que en opinión de Munuera (2005:51 en Alemán Bracho) "aunque lograron grandes reformas sociales no tienen un vínculo continuo ni directo con la historia en sí del Trabajo Social". Es el caso de Luis Vives (1492-1540) cuya nueva "forma de hacer" es lo que le hizo recibir el calificativo de precursor de la asistencia social organizada y del Trabajo Social ${ }^{8}$, si bien la idea que subyacía a su propuesta era la de peligrosidad de la pobreza para la estabilidad social del momento y de este modo la respuesta que se dio a este supuesto peligro fue el encierro de los pobres y por lo tanto la puesta en marcha de respuestas segregadoras del resto de la población. Con fines sanitarios y religiosos, su aportación supone la superación del "concepto de caridad individualista" y el comienzo de "la época de la beneficencia ${ }^{9}$ pública con intervención de los poderes competentes, aunque gestionada e ideologizada con excesivo predominio por la Iglesia Católica" (Las Heras y Cortajarena, 1979:58). Como afirma Casado (1988:111) las prescripciones de Luis Vives ${ }^{10}$ se refieren a dos cuestiones: intervención social pública y técnica de tratamiento de las situaciones de carencia. En opinión de

${ }^{8}$ Como señala Ander-Egg (1992:51-52)"Vives no sólo fue un precursor de la pedagogía y de la psicología, como se le reconoce desde estos campos profesionales, también lo fue del trabajo social". Lo que este mismo autor reconoce de Vives es que supo dar razón de porque había que prestar socorro a los de Vives es que supo dar razón de porque había que prestar socorro a los
pobres "con propuestas concretas de cómo hacer (los aspectos técnicos/operativos) y con qué hacer (los aspectos materiales y financieros)". Y afirma "que e libro de Juan Luis Vives, De subventione pauperum (El socorro de los pobres), ha sido la primera sistematización de las formas de ayuda a los necesitados, 0 si se quiere, el primer libro sobre la acción social con una expresa intencionalidad de atender el problema de la pobreza".

9 Según definición de Rubio Nombela, G. citado por Las Heras y Cortajarena en Introducción al Trabajo Social (1986:58), "La beneficencia sería, según la defien Introducción al Trabajo Social (1986:58), "La beneficencia sería, según la defición de pretensiones graciables de mera subsistencia (acogimiento alimentación, vestido, etc.) a favor de los indigentes, financiada con fondos públicos y privados".

10 Vives afirma vigorosamente la responsabilidad de las autoridades en lo que concierne a la situación y atención de los pobres (Casado, D., 1988:111). 
Moix (2006:47-48), Luis Vives "fue el primero en sostener la entonces revolucionaria tesis de que la prevención de la pobreza y el socorro de los pobres constituye una de las funciones propias e inexcusables del Estado".

$Y$ desde este nuevo enfoque que surgió en el siglo $X V$, teniendo en cuenta la situación socioeconómica de ese momento, se continuará el estudio de la historia de la acción social en el siglo XVII con San Vicente de Paúl (1581-1660) a quien se le atribuye el primer intento de estudiar las causas de la pobreza como medio de llegar a los efectos ${ }^{11}$, con un nuevo planteamiento de desinstitucionalización de los pobres, fundando en1617 las "Damas de la Caridad", así como también por el intento de organizar la actuación dirigida a ellos ${ }^{12}$, ya que los hospitales constituían en ese momento la pieza clave de la organización de la política social. En el estudio de esta época se hará referencia a la Ley de pobres (Poor Law) de 1601 en Inglaterra que en opinión de Ander Egg (1990:134) "marca un hito en el reconocimiento de las obligaciones sociales de carácter secular y con fuerza legal, que tiene el gobierno respecto a los necesitados" y unida a esta legislación y a la organización de la beneficencia la creación de la primera work house ${ }^{13}$ en Bristol en 1696 que junto con las denominadas ayudas domiciliarias constituían los dos tipos de ayuda que los pobres podían recibir de acuerdo con la legislación vigente y la consideración de que la pobreza respondía a una causa individual.

Se estudiará la labor de los reformadores en cuanto que supuso una forma de respuesta ante las necesidades sociales que si bien tampoco puede considerarse historia del Trabajo Social, forma parte de la historia de la acción social marcando

11 Ver De la Red (1993:27-28) en Aproximaciones al Trabajo Social, num.3. Colección Trabajo Social. Madrid.

12 Fundó en 1617 las "Damas de la Caridad" y en 1633 las "Hijas de la Caridad" y como señala Moix (2006:51) "San Vicente de Paúl, para orientar la actividad de sus colaboradores, formuló una serie de normas, previniéndoles contra la limosna o el auxilio indiscriminado, estableciendo el previo control de los "casos" por parte de la tesorería antes de de "visitarlos", efectuando una clasificación de los pobres en diversas categorías según su capacidad de automantenimiento".

${ }_{13}$ Ver Moix (2006:43-49) en Teoría del Trabajo Social para ampliar conocimientos sobre el significado de las casas de trabajo (work houses). 
unas directrices de actuación y unas formas de intervención que deben ser conocidas por los futuros profesionales del trabajo social como parte de una etapa en la que se da paso a otra más avanzada.

\section{La acción Benéfico Asistencial}

En el estudio de la historia de la acción social, se abordará cómo la caridad dio paso a la beneficencia, a la que Ander Egg (1990:132) considera "la institucionalización del ocultamiento de la pobreza"14 que en España viene regulada por la Ley de Beneficencia de 1822 y la Ley General de Beneficencia de 1849 y como afirma Casado (1988:113) estas regulaciones de la Beneficencia atribuyeron a los poderes públicos amplias responsabilidades aunque no significarán la desaparición de las formas tradicionales de satisfacción de las necesidades humanas y sociales que como señala este mismo autor (1992: 53) "la acción social por motivos religiosos de inspiración cristiana sigue jugando un importante papel". Haremos referencia a Don Juan Bosco o desde el protestantismo a Thomas Chalmers (17801847) a quien se le atribuyen la introducción de la necesidad de hacer estudios previos antes de actuar, dando una gran importancia a la ayuda vecinal en la asistencia a los pobres pero también porque "impuso en su parroquia un diseño de socorro de los pobres que es un claro precedente de lo que posteriormente se denominó Trabajo Social de casos (casework) y su influencia se dejó sentir en algunos principios y prácticas del Charity Organization Movement" como señala Aleman Bracho (2005:74) . Dedicaremos un espacio al conde Rumford (1753-1814) quien fue consciente de que "a las personas que recurrían a la mendicidad les impulsaban diferentes necesidades: trabajo, vivienda, escuela, alimentación, control y manejo del dinero, etc." (Alemán Bracho, C., 2005:72). De él se puede decir que consiguió disminuir la mendicidad en Múnich a través del plan que lleva su

${ }^{14}$ Para profundizar en el proceso que culmina en el siglo XIX con la aparición de la beneficencia pública consultar Historia del Trabajo Social de Ezequiel Ander Egg (1990:132-137). 
mismo nombre y que supuso "un ejemplo de administración de recursos en coordinación con la red industrial de la ciudad", que posteriormente se conoce como "el sistema Elberfeld" ${ }^{5}$. Y hasta aquí no habremos hecho como concluye Alemán (2005:74), sino, "buscar precedentes en las propuestas y contribuciones que determinados reformadores sociales realizaron" pero que en modo alguno son el origen de la disciplina o del Trabajo Social como profesión ${ }^{16}$.

Así, se estudiará el proceso histórico del nacimiento del Trabajo Social contextualizado en la transición del siglo XVIII al XIX que es cuando tal hecho tiene lugar según Malagón y Sarasola $(2005: 81 \text { en Alemán Bracho })^{17}$. El intenso proceso de cambio denominado Revolución Industrial, como consecuencia de las profundas transformaciones económicas y sociales que se inician a mediados del siglo XVIII y se prolongan hasta mitad de siglo XIX en Gran Bretaña, trajeron el aumento de la riqueza de la burguesía ${ }^{18}$ pero llevó consigo también la falta de bienestar de las clases desfavorecidas. Este proceso se vinculará a las innovaciones técnicas y sus consiguientes transformaciones estructurales en el proceso de producción de bienes que facilitaron el cambio hacia el sistema económico capitalista y a Inglaterra como primer país que recibió su primer ímpetu, aunque seguido por Bélgica, Francia, Alemania... En este contexto se hará referencia a la doctrina liberal, cuyo dogma central es la no-intervención del estado y donde el trabajador es considerado como una mercancía, sometido a condiciones infrahumanas que trataremos de estudiar a través de los contenidos teóricos pero fundamentalmente con el visionado de películas que ilustran y reflejan de forma excepcional el contexto en el que nace esta

${ }^{15}$ El sistema Elberfeld de acuerdo con el plan Runford quedó recogido en la obra de Runford, Ensayos políticos, económico, y filosóficos publicada en 1799 en Londres.

${ }_{16}^{16}$ Los elementos que de forma integrada convierten al Trabajo Social en una profesión según Alemán (2005:74) son: 1) un proceso metodológico determinado de estudio; 2) un proyecto de tratamiento para el cambio; 3) una serie de técnicas determinadas; 4) unos fines específicos; 5) una ética profesional; 6) un espacio profesional.

17 Ver Introducción al Trabajo Social de Alemán Bracho.

18 Para profundizar en el contexto en el que nace la profesión leer "Introducción al Bienestar Social" de Las Heras, P. y Cortajarena, E. (1986:61-66). 
profesión, que también podemos conocer a través de las lecturas de Engels en la sociedad Inglesa referidas por De las Heras y Cortajarena cuando "habla de los barrios obreros de Londres, Manchester y Liverpool, enumerando en su descripción todas las posibles lacras de aglomeración, suciedad, desorden urbano, contaminación, prostitución..." o de las del socialista utópico Considerat cuando nos pinta la parte de la sociedad parisina que vive sumida en "un caos en que más de la mitad de la población vive en tugurios caracterizados por el deterioro, mefitismo, inmundicia y miseria" Las Heras y Cortajarena, 1986:63).

Una vez analizado y estudiado este contexto los alumnos estarán en condiciones de entender el nacimiento de las respuestas asistencialistas que se concretaron en las leyes de pobres ${ }^{19}$ y sus reformas, en la existencia de los orfanatos y asilos cuyo mejor reflejo lo encontramos en las obras de Charles Dickens, sin pasar por alto que la coherencia con la teoría del libre mercado suponía que un desempleado no era susceptible de ayuda. En esta situación de total desprotección de miles de personas estudiaremos las reacciones de la clase trabajadora y de las propias organizaciones. Se estudiará la figura del socialista utópico Robert Owen $^{20}$ (1771-1858) y empresario progresista que como señala Miranda (2004:88) "pretendía conseguir el apoyo de los capitalistas para instaurar un régimen de vida más humanitario y, posteriormente, el llamado socialismo científico", consecuencia de la aportación teórica de Marx (18181883) y Engels (1820-1895) para quienes los fenómenos sociales no podían estudiarse y entenderse de forma separada ya que todos ellos estaban interconectados y por lo tanto al analizar la acción social desde esta perspectiva la conclusión a la que llega la clase trabajadora es que "la acción social no aparece como una cuestión de asistencia o de ayuda, sino como un

${ }^{19}$ Como señala Ander Egg (1992:54), en Inglaterra "la Ley de Pobres se remonta al año 1601. Pero es en la Reforma de la Ley de Pobres de 1834 cuando se dieron algunos pasos y evoluciones importantes en la organización de la beneficencia, partiendo de nuevas ideas relacionadas con la naturaleza de la pobreza y del propio papel del Estado en lo que concierne a su labor benéfico-asistencial".

20 Ver Las Heras, P. y Cortajarena, E. (1986:67) en Introducción al Bienestar Social para profundizar en la aportación de Robert Owen. 
problema estructural de la sociedad, hijo de la situación imperante" (Las Heras y Cortajarena, 1986:69).

\section{El nacimiento del Trabajo Social como profesión}

Para estudiar el nacimiento del Trabajo Social como profesión es preciso hacer referencia a la asistencia social cuyo nacimiento podemos situarlo en el cambio del Estado Liberal al intervencionista que se produce como consecuencia de la búsqueda del cambio social y a hechos tan importantes como son el surgimiento de la política social, como responsabilidad del estado. Como ejemplos, Londres, donde las sociedades caritativas y filantrópicas estaban desbordadas ante la demanda de asistencia a los necesidades y el de Alemania, con Bismarck ${ }^{21}$ donde la intervención del estado surge "como una forma de contrarrestar las luchas revolucionarias" (Ander Egg,1991:138) y la promulgación en este mismo país de la primera legislación sobre seguros sociales en los años ochenta del siglo XIX: de enfermedad (1883), de invalidez y vejez (1889), y accidentes de trabajo (1884) como afirma Ander Egg.

El estudio de esta etapa fundamental de la historia del Trabajo Social vamos a enfocarlo refiriéndonos a la influencia que en el campo de las ciencias sociales tuvo el positivismo que como señalan Estruch y Güell (1976:41) preconizaba la posibilidad de encontrar soluciones racionales y empíricas a los problemas sociales por medio de reformas y de adecuadas orientaciones a nivel individual. Como afirma Miranda (2004:37) "el Trabajo Social como profesión nace en Europa y en los Esta-

${ }^{21}$ Según Ander Egg, (1991:138) "Bismarck tuvo no pocas dificultades parlamentarias para hacer aprobar su programa: los manchesterianos se oponían fuertemente (el liberalismo económico en estado puro seguía vigente). Sin embargo, aunque parezca una paradoja o contradicción -en lo más profundo no lo es- la seguridad social para los trabajadores aparece por primera vez en la historia promovida por un gobierno conservador. Sólo en apariencia es una contradicción: lo que de verdad interesa con todas estas disposiciones no es que los trabajadores tengan seguridad social, sino que las ideas socialistas no avancen, trabajadores téngan seguidad social, sino que las ideas socialistas no avancen, que la agitación obrera sea controlada y que los obreros se vinculen al régimen imperial...". 
dos Unidos de manera más o menos simultánea,... como parte del proyecto global de las Ciencias Sociales, ni antes ni después, y por los mismos motivos, en el mismo contexto social y político, y en permanente diálogo con ellas".

En Inglaterra la crítica a las formas de ayuda al necesitado, la aparición de personas que vivían de la limosna, así como el ambiente de reivindicaciones y de movimientos obreros lleva a paliar una situación angustiosa por medio de servicios prestados por instituciones públicas y privadas prácticamente desbordas por la demanda de asistencia que unidos a los nuevos campos de intervención del Estado facilitarán el nacimiento de esta nueva profesión. Por su importancia en la historia de la Acción Social se estudiará en este contexto ${ }^{22}$ la aparición de las Sociedades de Organización de la Caridad, conocidas por sus siglas en inglés, COS (Charity Organization Society) en 1869 y su principal protagonista Octavia Hill. Como consecuencia de la preocupación por las tareas de asistencia social y con la finalidad de coordinar las actividades de acción benéfica, como señala Ander Egg (1992:54-55), la creación y desarrollo de las Sociedades de Organización de la Caridad (COS) constituyen el último hito que lleva a la institucionalización del Trabajo Socia como profesión. Especialmente importante será el estudio de las orientaciones básicas de la COS y la mención a la aparición de

${ }^{22}$ El contexto en el que nace la COS según Ander Egg (1992:55): "En la Inglaterra de los años sesenta, existía un estado de opinión bastante desfavorable a la ayuda gubernamental para atender a los pobres. En plena vigencia de las ideas liberales y las de un darwinismo social al estilo spenceriano que, por razones de selección, proponía poco menos que dejar morir a los pobres, no se concebía que el Estado asumiese responsabilidades en lo concerniente a la ayuda a los necesitados.

En ese entonces las críticas a las formas de ayuda al necesitado se centraban en dos cuestiones fundamentales: una, que se estaban creando pordioseros, ya que se acostumbraba a determinada gente a vivir de la limosna, y otra que la ayuda constituye un verdadero despilfarro de dinero, puesto que se hace que la ayuda constituye un verdadero despilfarro de dinero, puesto que se hace
sin control. Dentro de esta situación y preocupado principalmente por las tareas sin control. Dentro de esta situación y preocupado principalmente por las tareas
de asistencia social, en 1868 el pastor Henry Solly recomendó crear un consejo de coordinación de actividades de acción benéfica, tanto en el ámbito de la acción pública como de la acción privada. Teniéndose en cuenta esta recomendación, al año siguiente se creó la "Sociedad para la organización del socorro caritativo y la represión de la mendicidad". Y dice Ander Egg: "bien pronto se cambió de nombre y se convitió en la COS. Su creación fue uno de los camb́r de nombre y se convirtó en la COS. Su creación fue uno de los pasos más importantes en la concepción y organización de las prácticas asistenciales". 
los llamados "charity workers" y "friendly visitors" que desde una actividad voluntaria aplicarán las reglas del posterior trabajo social individualizado y la aparición de institutos para la formación de este personal en 1873. Otro aspecto importante de estudio es el proceso evolutivo que siguió la COS que pasó de considerar al individuo el causante principal de su deterioro, al reconocimiento de otros factores objetivos y mantenedores de la pobreza, como el desempleo, la enfermedad, las deudas, las viviendas insalubres, etc. como afirma Alemán Bracho (2005:101).

Continuaremos estudiando las figuras de Josephine Shaw Lowell, y Jane Addams que representan las dos corrientes e iniciativas imprescindibles para entender el nacimiento del Trabajo Social como profesión y disciplina. Josephine Shaw Lowell (1843-1905) una de las líderes fundadoras de la COS en Nueva York, partidaria de la limitación de la intervención pública (como la COS inglesa), el estudio de las personas susceptibles de ayuda y la implicación del entorno en la atención de las necesidades. Jane Addams (1860-1935) fue quien importó el movimiento Settlements inglés a EEUU y como afirma Alemán Bracho (2005:119) "se inscribe en la corriente del Trabajo Social que defendió la idea de la reforma social, que planteaba niveles de exigencia mayores de justicia y equidad que la respaldada por la tradición conservadora de la profesión y que, en los orígenes, encarnó perfectamente la COS”.

Especial atención dedicaremos a Mary Richmond (18611928) revitalizadora de las COS en Estados Unidos en 1891, contemporánea de las anteriores, se destacará su especial contribución al nacimiento del Trabajo Social como profesión y disciplina, ya que según Malagón y Sarasola ${ }^{23}$ supo dotarlo de un "contenido teórico sistematizado; fue su inventora conceptual, la que teorizó y sistematizó el Trabajo Social, la que formalizó sus técnicas y sus contenidos; estableció, como objetivos del Trabajo Social, no sólo educar a la población, sino también investigar y denunciar situaciones sociales injustas". Supo, además, captar la necesidad de formación de quienes intervenían en Trabajo Social, estudió las corrientes sociológicas y filosóficas entonces

${ }^{23}$ Malagón, J.L. y Sarasola, J.L en Introducción al Trabajo Social de Alemán Bracho (2005:122) 
en boga (William James y John Dewey, pragmáticos receptores del positivismo de Herbert Spencer), se introdujo en la psicología social con George Mead y en 1897 en la Conferencia Nacional de Instituciones de Caridad y Corrección celebrada en Toronto, expuso la necesidad de crear una escuela para la formación de trabajadores sociales, lo que supuso un año después la creación de la Escuela de Filantropía de Nueva York, de la que fue docente, y que en 1918 pasó a denominarse Escuela de Trabajo Social en la que ocupó la Cátedra de Caso Social Individual. La investigación durante años le llevó a formular la primera teoría del Trabajo Social que refleja en su libro Diagnosis social, publicado en 1917. Estableció las bases científicas para una nueva profesión a través del inicio del Trabajo Social de casos antes de sistematizarlo y teorizarlo, algo que sirvió para distinguir al Trabajo Social de otras disciplinas y profesiones.

Realizaremos un breve recorrido cronológico de la creación en Europa de las diferentes escuelas, empezando por la de Ámsterdam en 1899, la de Berlín en 1908, la de Bélgica en 1920 y la de Barcelona en 1932 que surgió como filial de esta última.

${ }^{24}$ Para De la Red (1993) los elementos requeridos para afirmar que el Trabajo Social pueden ser considerado como una disciplina se concretan on los siguienprogreso de la sociedad y de los saberes; concreta y sensible respecto a progreso de la sociedad y de los saberes; concreta y sensible respecto a los niveles y áreas de intervención; integradora de todos los elementos con los que se halla implicada; y marca los fines propios y específicos.

${ }^{25}$ Juan Estruch y Antonio M, Güell (1976):" El primero, su nacimiento, a finales del siglo XIX y principios del XX, está marcado por las consecuencias de los cambios originados por la revolución industrial de Occidente. El segundo estaría comprendido entre el final de la Primera Guerra Mundial y el periodo de la gran depresión económica; se trata de una época en la que es preciso atender a las necesidades provocac necesidades provocads por elcon arrollan las tecnicas de grupo y de comunidad, y el asistente social colabora como un técnico más en la organización y el desarrollo comunitarios. Es as mismo el periodo en el que se aprecia en Europa la introducción de la influencia católica en el trabajo social; en 1920, promovida por el cardenal Mercier, se funda en Bélgica la primera Escuela Católica de Servicio Social y años más tarde se funda en Milán. Por último la tercera etapa de desarrollo se sitúa a partir de la conclusión de la Segunda Guerra Mundial: es el periodo que coincide con los adelantos de las ciencias sociales, en esta etapa ha influido elimpulso con los adelantos de las ciencias sociales, en esta etapa ha infludo el im dado al trabajo social por la ONU a través de congresos, seminarios y programas de desarrollo y políticas sociales. 
Distinguiremos entre disciplina y profesión y en la consideración del Trabajo Social como disciplina científica ya que cumple todos los elementos ${ }^{24}$ que le son requeridos para ello.

Haciendo historia para una mejor comprensión de la asignatura seguiremos a Juan Estruch y Antonio M, Güell en "Sociología de una profesión. Los asistentes sociales"25 (1976) haciendo referencia a los tres momentos históricos que han contribuido al desarrollo del trabajo social.

\section{EI Trabajo Social en nuestros contextos geográficos más próxi-} mos y hasta la actualidad

Nos referiremos al proceso de creación de la profesión en España que se había iniciado de manera similar a la de otros países europeos aunque al carecer de los estudios previos de investigación de estos se basó en el diseño y contenido de la escuela católica de Bélgica y también al modelo francés pero que muy pronto se vio paralizado como explica Tomasa Báñez por la Guerra Civil, momento a partir del cual "el carácter religioso se vio matizado por el nacional catolicismo, por lo que el contenido confesional de la profesión perduró mucho más que en otros países, ya que la asistencia social, como forma de caridad organizada, tuvo un importante papel en el proceso de legitimación del régimen franquista y de cristianización de la sociedad española" (Bañéz, 2003:72) y además tuvo una orientación más asistencialista. Como expone Moix el Trabajo Social comenzó llamándose Servicio Social, lo que indujo a confusión, como si Trabajo Social y Servicios Sociales ${ }^{26}$ fueran lo mismo. Desde 1932, año en que apareció la primera escuela hasta 1952 solo se crearon tres escuelas en España. De las 35 que había en 1964 según Moix, cinco dependían de la Sección Femenina una de las Hermandades del Trabajo, otra de la Universidad de Navarra y el resto de la Federación Española de Escuelas de la Iglesia Servicio Social. En 1967 se crearon las Escuelas Oficiales de Asistencia Social de Zaragoza y de Madrid. Se estudiará

${ }^{26}$ Para profundizar en las definiciones de Trabajo Social y Servicios Sociales ver "La práctica del Trabajo Social" de Manuel Moix Martínez (2006:167). 
los años 70 como el período que supone el inició de cambio en la profesión y su defensa, la reestructuración colegial y la eliminación de la beneficencia pública del texto constitucional. Destacaremos el II Congreso Nacional de Asistentes Sociales en Madrid en 1972 en el que ya se apostó por la actitud de cambio, influencia del "Movimiento de la Reconceptualización" y las jornadas celebradas en Pamplona en 1977 donde se formularon las nuevas pautas de acción. Continuaremos con el estudio de los años 80 que, sobretodo, supusieron la creación de un sistema público de Servicios Sociales, la sustitución de los centros de beneficencia por nuevos departamentos de Servicios Sociales y la aplicación de una política de igualdad de atención a todos los ciudadanos, que se apoyó en el IV Congreso en Valladolid, en 1980. En esta década también se crearon los colegios de Asistentes Sociales y las Escuelas de Asistentes Sociales cambiaron su nombre por el de Escuelas de Trabajo Social incorporándose a la Universidad. A partir de la década de los 90, el estudio se abordará teniendo en cuenta que significó la consolidación de los cambios de las décadas anteriores y el acercamiento de nuevo al Trabajo Social en Europa.

Aragón constituye el contexto geográfico más próximo desde el que se abordará el estudio de la profesión de Trabajo Social que como señala Tomasa Báñez (2003:178) surge en esta región en los años cincuenta, muy vinculada a lo femenino, a las mujeres burguesas, a la iglesia católica y las nuevas formas de atender a la pobreza desde finales del S-XIX ${ }^{27}$ en Europa, que

${ }^{27}$ Como señala Báñez (2003) respecto a la aplicación de las nuevas formas de atender a la pobreza: ".la atención de los pobres no podía limitarse, tal como había ocurrido hasta ese momento histórico, a paliar las consecuencias individuales y de carácter material de la pobreza, sino que debía incluir una importante labor de moralización y control social de los pobres, ya que se consideraba que podía evitar el enfrentamiento entre el trabajo y el capital, creando el clima social y político adecuado para el pleno desarrollo del capitalismo. Al igual que en otros países europeos, la elaboración de estas nuevas formas de atención a en otros países europeos, la elaboración de estas nuevas formas de atención a la pobreza en Aragón fue consecuencia de las transformaciones del contexto en la concepción ideológica de la pobreza y de los pobres, influidos en el caso de nuestra región, por la ideología del régimen franquista, que pretendía superar la lucha de clases basándose en el concepto de fraternidad católica y unidad nacional Para esta labor se precisaba de la importante colaboración de sia institución que adquiere un papel de adoctrinamiento importante dentro de régimen". 
lejos de afrontar las causas se limitaban a la atención de las consecuencias de la misma. Aunque posteriormente el surgimiento de movimientos sociales y políticos facilitó la entrada en este escenario de mujeres con diferentes características.

Se hará referencia a aspectos de la profesión en sus inicios, caracterizada por una atención de las necesidades desde una orientación caritativa y asistencial en los años cincuenta, unida al intento de la iglesia católica de profesionalizar estas tareas caritativas impartiendo estudios de asistencia social con la creación de la Escuela de Asistentas Sociales San Vicente de Paúl de Zaragoza en 1957, pero sin dar a penas importancia a los contenidos, a las técnicas y mucho menos por lo que respecta a las condiciones de los profesionales, sin remuneración económica, situación que inicia su cambio con la creación de la Escuela de la Universidad Laboral Femenina ${ }^{28}$ en 1967 y sobretodo se hace patente a partir de la transición democrática en España que desde los años 70 inicia la consolidación de la formación de esta profesión, la tecnificación profesional y el compromiso político de los profesionales del Trabajo Social. Durante los años 80 y 90 se produce el reconocimiento universitario, el cambio de asistentes sociales a trabajadores sociales y "como consecuencia de la creación de los servicios sociales" (Bañez, 2003:168), la consideración de los trabajadores sociales como técnicos de la acción social.

\section{Conclusión}

En este artículo se ha pretendido exponer los contenidos de la asignatura de Historia del Trabajo Social que los futuros Diplo-

${ }^{28}$ En opinión de Báñez (2003) "la Escuela de la Universidad Laboral Femenina supuso una oportunidad para las hijas de trabajadores procedentes de medio rural. Junto con esos cambios en la procedencia geográfica y social de las estudiantes de trabajo social, es preciso señalar también cambios en las motivaciones para entrar en la profesión. Estas motivaciones fueron modificándose progresivamente desde las motivaciones religiosas a las motivaciones sociales progresivamente desde las molvaciones religiosas a las molivaciones sociales y politicas y se relacionaron con las oportunidades de encontrar una salida laboral a través de los estudios de asistente social". 
mados deben estudiar para entender y reflexionar sobre los orígenes de la profesión de trabajador social, para facilitar una actuación acorde con la realidad social actual, tratando de evitar actuaciones que dentro del proceso de formación de la profesión han quedado superadas y obsoletas perteneciendo al recuerdo de un pasado no muy lejano.

\section{Bibliografía}

ANDER-EGG, E. (1992). Introducción al Trabajo Social., Madrid: Siglo Veintiuno, Editores.

ANDER-EGG, E. (1990). Historia del Trabajo Social., Buenos Aires: Editorial Humanitas.

BAÑEZ, T. (2003). El trabajo Social en Aragón. El proceso de profesionalización de una actividad feminizada. Tesis Doctoral. Tarragona.

BERGER, P., LUCKMANN, T. (1998). La construcción social de la realidad. Buenos Aires: Amorrortu editores.

CASADO, D. (1988). Introducción a los servicios sociales. Madrid: Acebo.

DE LA RED, N. (1993). Aproximaciones al Trabajo Social. Madrid: Consejo General.

DUNLOP, J., GALENSON, W. (1985). El trabajo en el siglo XX. Madrid: Ministerio de Trabajo y Seguridad Social.

ESCARTÍN, Ma J. (1992). Manual del Trabajo Social. Alicante: Editorial Aguaclara.

ESTRUCH, J., GÜELL, A. (1976). Sociología de una profesión. Los asistentes sociales. Barcelona: Ediciones Península.

FERNÁNDEZ, T., ALEMÁN BRACHO, C. (2005). Introducción al trabajo social, Madrid: Alianza Editorial.

FRIEDLANDER, W.A. (1989). Dinámica del Trabajo Social. México: Editorial Pax México.

GARRIDO, F. (1970). Historia de las clases trabajadoras. 1. El esclavo. Algorta (Vizcaya): Edita Zero.

GARRIDO, F. (1970). Historia de las clases trabajadoras.2. El siervo. Algorta (Vizcaya): Edita Zero.

GARRIDO, F. (1971). Historia de las clases trabajadoras.3. El proletario. Algorta (Vizcaya): Edita Zero.

GARRIDO, F. (1971). Historia de las clases trabajadoras.4. El 
trabajador asociado. Algorta (Vizcaya): Edita Zero.

GINER, S. (1992). Historia del Pensamiento Social. Barcelona: Ariel. HAMILTON, G. (1960). Teoría y Práctica. Trabajo Social de Casos, México: Ediciones Científicas.

LAS HERAS, P., CORTAJARENA, E. (1986). Introducción al bienestar social. Madrid: Consejo General.

MIRANDA, M. (2004). De la caridad a la ciencia. Pragmatismo, Interaccionismo simbólico y Trabajo Socia. Zaragoza: Mira Editores.

MOIX, M. (1991). Introducción al Trabajo Social. Madrid: Editorial Trivium. MOIX, M. (2006). Teoría del Trabajo Social. Madrid: Editorial Síntesis.

PAYNE, M. (1995). Teorías contemporáneas del Trabajo Social. Barcelona: Ediciones Paidos.

SOYDAN, H. (2004). La historia de las ideas en el Trabajo Social. Valencia: Consejo General.

ZAMANILLO, T., GAITÁN, L. (1991). Para comprender El Trabajo Social, Estella (Navarra): Editorial Verbo Divino. 